\title{
Effects of Internal Control System on Performance of Local Governments in Sisaket Province
}

\author{
Piyachat Thongpaeng* \\ Department of Accounting, Faculty of Business Administration and Accounting \\ Sisaket Rajabhat University \\ Sisaket Province, Thailand \\ *piyachat.t@sskru.ac.th
}

\begin{abstract}
This study aimed to study the effects of internal control on performance of local governments in Sisaket Province. The independent variables used in this study were 5 factors of the internal control system: control environment, risk assessment, control activities, information and communications and monitoring. The dependent variables were the performances of the local governments in Sisaket Province, which consisted of operational efficiency and effectiveness, financial report reliability and compliance with applicable laws and regulations. The researcher used questionnaires as a tool to collect data from samples of 40 local governments in Sisaket Province by submitting 2 sets of questionnaires each. The 80 sets were replied, which represented $100 \%$. The descriptive statistics and multiple regression were used in data analysis. The study found that all factors affected performances of local governments in Sisaket Province as follows: monitoring, control activities, information and communications, control environment and risk assessment, respectively, with the statistical significance at the level of $p$ $<0.01$.
\end{abstract}

Keywords-internal control, internal control and internal audit, accounting, performances, local governments

\section{INTRODUCTION}

As per the Constitution of the Kingdom of Thailand B.E. 2550 (2007), the local government is freely authorized to assign government policy, personnel management, finance administration and its own specific authority. Currently, the change of technology is causing government agencies to reform their system to become better and more efficient. In addition, the good governance is able to implement control methods in performance in order to reduce risks and errors by applying the internal control system as a tool to control and supervise various performances efficiently, reduce risk and errors in order to achieve its objectives. The internal control system helps to protect and maintain the assets of the organization in order to use the resources worthily and efficiently. Furthermore, the performances are appropriately correct and accurate with the procedures [1].

Regarding the importance of the mentioned internal control system, the government agencies have established guidelines by applying the internal control system from the internal control system of The Committee of Sponsoring Organizations of the Treadway Commission or COSO, an internal control system of different factors in administration which is accepted worldwide [2]. The State Audit Office of the Kingdom of Thailand [3] has assigned an internal control standards by issuing regulations of the State Audit Commission on the setting of internal control standards B.E. 2544 (2001) which is defined the definition of internal control as the operational process that is provided by the supervisors, executives and personnel in the audit unit. It is set to reasonably assure that the performance will achieve the objectives of internal control effectively and efficiently with property protection, error prevention, wastage reduction and corrupt reduction. Moreover, it increases reliability of financial reports in order to comply with laws, regulations and cabinet resolutions which is the responsibility of the supervisor to implement the standards as a guideline in setting up an internal control system.

Since the internal control is a system that encourages the agency to perform with the assigned policies, practices and orders [4]. The Department of Local Administration has adopted the guidelines of the regulations as mentioned above to use as a criteria of government performance in good governance in the mission of people's happiness. As a result, the local governments can use resources efficiently and worthily which affects the financial reports to be accurate [5]. However, the investigation revealed that the arrangement of internal control system in most local governments were still inaccurate and incomplete. Due to a lack of knowledge and understanding among administrators and staffs to implement the internal control standards including a lack of clarification in the practice guidelines [6].

Therefore, according to laying down of the internal control system in government agencies which is believed that it can be guidelines for organizations to reduce the risk of corruption, to use resources efficiently and effectively as well as to have accurate complete and reliable financial reports in order to achieve the objectives. The researcher was interested in studying the effects of the internal control system in order to know whether the internal control system affected the performance of the local governments in Sisaket Province or not. The purpose was to apply the results as guidelines for 
improving the internal control system of the local governments to perform effectively and efficiently.

\section{OBJECTIVES}

To study the effects of internal control on performance of local governments in Sisaket Province.

\section{RESEARCH EXTENTS}

\section{A. Materials and Methods}

The researcher studied the effects of the internal control system on the performance of the local governments in Sisaket Province under the scope of internal control system based on the internal control standards set by the State Audit Office of the Kingdom of Thailand.

The conceptual framework for this research based on the 5 factors of the internal control system. The results of performance achieved the internal control system guideline set by the State Audit Office of the Kingdom of Thailand as the conceptual framework in Figure 1.

\begin{tabular}{|l|l|}
\hline \multicolumn{1}{|c|}{ Independent } & \multicolumn{1}{c|}{ Dependent } \\
\hline \multicolumn{1}{|c|}{ Internal Control System } & \multicolumn{1}{c|}{ Performances } \\
1. Control environment & 1. Operational efficiency and \\
2. Risk assessment & effectiveness \\
3. Control activities & 2. Financial report reliability \\
4. Information and & 3. Compliance with applicable \\
communications & laws and regulations \\
5. Monitoring & \\
\hline
\end{tabular}

Fig. 1. Conceptual framework.

The hypotheses for the study of effects of the internal control system on the performance of the local governments in Sisaket Province were assigned as follows:

1) Hypothesis 1: Internal control system affected the performance of the local governments in Sisaket Province.

2) Hypothesis 2: Internal control system affected the efficiency and effectiveness of the performance of the local governments in Sisaket Province.

3) Hypothesis 3: Internal control system affected the reliability of the local governments' financial reports in Sisaket Province.

4) Hypothesis 4: Internal control system affected the compliance with applicable laws and regulations of the local governments in Sisaket Province.

\section{B. Population and Samples}

The researcher assigned the population and samples for the study of the effects of the internal control system on the performance of local governments in Sisaket Province based on the local governments in Sisaket Province consisting of 40 local governments in 4 districts: Rasi Salai District, Khun Han District, Si Rattana District and Wang Hin District.
The samples were divided by sampling method as follows: 1) purposive sampling was used with the population from the local governments in Sisaket Province classified by the form of local governments based on the State Administration Regulation Act B.E. 2534 (1991) as Tambon Administrative Organizations and 2( simple random sampling was used by drawing lots to get 80 samples.

\section{Instrumentation}

The instruments used in this research were closed ended questions divided into 3 parts:

1) Part 1: General information of the respondents consisted of gender, age, level of education, work experience, size of agency, and position in local governments in multiple choice form.

2) Part 2: Opinions on the results of internal control were in the form of Likert rating scale divided into 5 levels: strongly agree, agree, moderately agree, slightly agree and least agree.

3) Part 3: Opinions on performance were in the form of Likert rating scale divided into 5 levels: strongly agree, agree, moderately agree, slightly agree and least agree.

Part 2 and part 3 were sorted by the opinions of the samples into 5 levels ${ }^{6}$ as follows:

- 5 indicates "Strongly agree"

- 4 indicates "Agree"

- 3 indicates "Moderately agree"

- 2 indicates "Slightly agree"

- 1 indicates "Least agree"

Afterwards, the opinions on the effects of internal control system on performance of local governments in Sisaket Province were interpreted based on the following criteria [7]:

- Average of 4.51 - 5.00 indicates "Strongly agree"

- Average 3.51 - 4.50 indicates "Agree"

- Average 2.51 - 3.50 indicates "Moderately agree"

- Average 1.51 - 2.50 indicates "Slightly agree"

- Average 1.00-1.50 indicates "Least agree"

\section{Data Collection}

The survey research of the effects of the internal control system on performance of the local governments in Sisaket Province collected data from local governments in Sisaket Province. The researcher assigned the chief executives and the accounting/financing officers to be the respondents by answering questions which researcher submitted at the Tambon Administrative Organizations in 4 districts with 2 sets each. 
The 80 complete questionnaires were replied and then were analyzed statistically by descriptive statistics and inference statistics.

\section{E. Data Analysis}

- The researcher statistically analyzed data using a software package by examining the completeness and accuracy of the returned questionnaires from the samples. Then, the data were recorded and inputted in the form of code, examined and processed as per research objectives.

- The researcher assigned the chief executives and the accounting/financing officers to be the respondents.

\section{F. Statistics}

- The descriptive statistics used in describing general characteristic of the samples were percentage, mean and standard deviation. The analysis results were presented in table format followed by description.

- The reference statistic used to test the hypotheses was multiple regression analysis as follows:

- Hypothesis 1: Internal control system affected the performance of the local governments in Sisaket Province.

- Hypothesis 2: Internal control system affected the efficiency and effectiveness of the performance of the local governments in Sisaket Province.

- Hypothesis 3: Internal control system affected the reliability of the local governments' financial reports in Sisaket Province.

- Hypothesis 4: Internal control system affected the compliance with applicable laws and regulations of the local governments in Sisaket Province.

\section{RESULTS}

The analysis of general data of the respondents revealed that the majority of the samples were males ( 67.0 percent) and female (33.0 percent). Most of the samples aged 45 years or more (56.0 percent) followed by 35-44 years (37.7 percent). Most of them held bachelor's degree or equality (37.3 percent) followed by graduate degree (33.7 percent). Moreover, most of them had work experience in the local governments more than 6 years (31.0 percent). The respondents were chief executives and the accounting/financing officers with the same amount (50.0 percent).

The overall analysis of level of opinion on the internal control system consisted of 5 aspects as shown in Table 1.
TABLE I. THE OVERALL LEVEL OF OPINION ON THE INTERNAL CONTROL SYSTEM

\begin{tabular}{|l|c|l|l|}
\hline \multicolumn{1}{|c|}{ Internal Control System } & X & S.D. & Level of opinion \\
\hline 1. Control environment aspect & 3.64 & 0.59 & Agree \\
\hline 2. Risk assessment aspect & 3.38 & 0.66 & Moderately agree \\
\hline 3. Control activities aspect & 3.66 & 0.65 & Agree \\
\hline $\begin{array}{l}\text { 4. Information and communications } \\
\text { aspect }\end{array}$ & 3.60 & 0.64 & Agree \\
\hline 5. Monitoring aspect & 3.55 & 0.60 & Agree \\
\hline Overall & 3.51 & 0.51 & Agree \\
\hline
\end{tabular}

From Table 1, it was found that the overall analysis of level of opinion on the internal control system was at "Agree" level ( $X=3.56$, S.D $=0.51$ ). When considering each aspect, the results of 4 aspects were at "Agree" level: control activities aspect $(X=3.66$, S.D $=0.65)$, control environments aspect ( $=3.64$, S.D = 0.59), information and communications aspect $(X=3.60, S . D=0.64)$ and monitoring aspect $(X=3.55$, S.D $=0.60$ ), while the risk assessment aspect was at "Moderately agree" level ( $\mathrm{X}=3.38, \mathrm{~S} . \mathrm{D}=0.66$ ).

The overall analysis of level of opinion on the performance consisted of 3 aspects as shown in Table 2.

TABLE II. The Overall Level of Opinion on the Performance

\begin{tabular}{|l|c|l|l|}
\hline \multicolumn{1}{|c|}{ Performance } & X & S.D. & $\begin{array}{l}\text { Level of } \\
\text { opinion }\end{array}$ \\
\hline 1. Operational efficiency and effectiveness & 3.57 & 0.60 & Agree \\
\hline 2. Financial report reliability & 3.98 & 0.65 & Agree \\
\hline $\begin{array}{l}\text { 3. Compliance with applicable laws and } \\
\text { regulations }\end{array}$ & 3.86 & 0.58 & Agree \\
\hline Overall & 3.80 & 0.53 & Agree \\
\hline
\end{tabular}

From Table 2, it was found that the overall analysis of level of opinion on performance was at "Agree" level ( $\mathbb{X}=3.80$, SD $=0.53)$. When considering each aspect, the results were all at "Agree" level as followed: financial report reliability aspect ( $\mathrm{X}=3.98, \mathrm{SD}=0.65)$, compliance with laws and regulations $(\mathrm{X}=3.86, \mathrm{SD}=0.58)$ and operational efficiency and effectiveness $(X=3.57, \mathrm{SD}=0.60)$.

The results of hypotheses testing analysis using multiple regression analysis with prior testing on the preliminary agreement in the supportive linear regression analysis, it showed that:

- The error resulted from predicting were normally distributed considering from the arrangement near the straight line.

- The error resulted from predicting was equal to zero on average.

- The error resulted from predicting was constantly varied. 
- There was no independent variable in self-correlation (no multicollinearity) considered from the Variance Inflation Factor (VIF) ranging at 1.866-2.275 which was less than 10 without multicollinearity.

However, the researcher tested the relationship between the variables of the internal control system and the performance of the local governments in Sisaket Province by testing the correlation coefficient. It was found that the correlation coefficient of the internal control system variable and the performance was between $0.302-0.774$ with the statistical significance at the level of 0.01 as shown in Table 3 .

TABLE III. THE RESUlTS OF MULTIPLE REgRESSION OF THE INTERNAL CONTROL SYSTEM AFFECTING THE OVERALl PERFORMANCE

\begin{tabular}{|c|c|c|c|c|c|}
\hline $\begin{array}{c}\text { Internal Control } \\
\text { System }\end{array}$ & b & $\begin{array}{c}\text { Std } \\
\text {.Error }\end{array}$ & $\boldsymbol{\beta}$ & $\mathbf{T}$ & Sig \\
\hline Constant & 0.917 & 0.123 & & 7.484 & 0.000 \\
\hline $\begin{array}{l}\text { 1. Control } \\
\text { environment aspect }\end{array}$ & 0.136 & 0.045 & 0.152 & 3.050 & 0.002 \\
\hline $\begin{array}{l}\text { 2. Risk assessment } \\
\text { aspect }\end{array}$ & -0.102 & 0.036 & -0.127 & -2.825 & 0.005 \\
\hline $\begin{array}{l}\text { 3. Control activities } \\
\text { aspect }\end{array}$ & 0.164 & 0.040 & 0.203 & 4.028 & 0.000 \\
\hline $\begin{array}{l}\text { 4. Information and } \\
\text { communications } \\
\text { aspect }\end{array}$ & 0.157 & 0.041 & 0.190 & 3.843 & 0.000 \\
\hline 5. Monitoring aspect & 0.442 & 0.045 & 0.503 & 10.109 & 0.000 \\
\hline
\end{tabular}

Statistical significance at the level of 0.01
From Table 3, it was found that the coefficient of multiple regression was 0.824 , which was able to predict the overall performance at $68 \%$ with the predictive error of 0.300 . When considering the coefficient of multiple regression of the internal control system affecting the overall performance of the local governments Sisaket Province, it was found that the factors of the internal control system of all aspects affected the performance of the organizations as follows: monitoring aspect $(\beta=0.503)$, control activities aspect $(\beta=0.203)$, information and communications aspect $(\beta=0.190)$, control environment aspect $(\beta=0.152)$ and risk assessment $(\beta=0.127)$. Therefore, the researcher accepted the hypothesis 1 , internal control system affects the performance of the local governments in Sisaket Province, while hypothesis 2-4 were partially accepted.

\section{SUMMARY AND DISCUSSION}

From the study of the effects of the internal control system on the performance of the local governments in Sisaket Province, the overall results revealed that the factors of control environment aspect, risk assessment aspect, control activities aspect, information and communications aspect and monitoring aspect affected the performance of the local governments in Sisaket Province as discussed individually in Table 4.

TABLE IV. The INDIVIDUAl Discussion of THE StUdy RESUlTs IN 5 AsPeCts

\begin{tabular}{|c|c|}
\hline $\begin{array}{c}\text { Internal control system } \\
\text { (5 aspects) }\end{array}$ & Discussion \\
\hline $\begin{array}{l}\text { 1. Control environment } \\
\text { aspect }\end{array}$ & $\begin{array}{l}\text { Since the proper control environment will support the personnel to be aware of their duties and responsibilities which are able to } \\
\text { affect the performance in the agencies. The agencies can create a good control environment by assigning policies, practice } \\
\text { guidelines as well as rules of morality and ethics as a good practice. In addition, they should be clearly written and thoroughly } \\
\text { informed the personnel in the agencies in order to make personnel understand their assigned duties, which is in accordance with } \\
\text { Nureeya Sanbako [8], who found that the organizations assigning the management structure of operating policy for personnel, they } \\
\text { were aware of their own duties and responsibilities. Therefore, these guidelines in assigning a good control environment in the } \\
\text { agencies. } \\
\text { However, when considering each aspect, it was found that the control environment of the internal control system did not affect the } \\
\text { financial report reliability. It can be explained that the control environment is only a factor that helps the personnel to understand } \\
\text { their duties and responsibilities, while the preparation of financial reports is based on accounting standards guidelines. }\end{array}$ \\
\hline $\begin{array}{l}\text { 2. Risk assessment } \\
\text { aspect }\end{array}$ & $\begin{array}{l}\text { Regarding the perspective of samples, the opinion was at "Moderately agree" level of opinion on risk assessment. The reasons may } \\
\text { be because personnel may not pay attention in risk prevention that may arise in the agencies. In addition, the criteria have not yet } \\
\text { been assigned for considering and rating risks or assessing the risk that may arise in the working. There is no worthiness } \\
\text { consideration of the cost in risk management. However, the staff in the agencies lack of sufficient knowledge and understanding of } \\
\text { the internal control system, which is in accordance with Nureeya Sanbako [8], whose study was found that the educational } \\
\text { institutes did not pay attention to risk assessment, especially the review of the performance at the activity level to verify that } \\
\text { educational institutions achieved the school objectives because assigning the objectives was important to determine that } \\
\text { educational institutions performed as assigned criteria. } \\
\text { When considering each aspect, it was found that the risk assessment aspect of the internal control system did not affect the } \\
\text { financial report reliability. The samples' perspective revealed that the criteria for determining risk, ranking and internal risk } \\
\text { assessment affected the performance of asset custody from excessive loss or corruption. The preparation of correct financial } \\
\text { reports was overlooked as the accounting principles of the agency, which is in accordance with State Audit Office of the Kingdom } \\
\text { of Thailand [3] who indicated that the risk assessment was a process for analyzing risks, identifying and implementing control } \\
\text { methods to prevent and reduce risks in order to comply performance with its objectives efficiently and effectively. }\end{array}$ \\
\hline
\end{tabular}


Table 4. Cont.

\begin{tabular}{|c|c|}
\hline $\begin{array}{l}\text { 3. Control activities } \\
\text { aspect }\end{array}$ & $\begin{array}{l}\text { Since the control activities in assigning duties of chief executives to subordinate executives to be able to perform duties on their } \\
\text { behalf, it was clearly written that this practice was based on the principles of rules and regulations of the agencies [9]. As found } \\
\text { that members of the cooperative group greatly paid attention on the control activities within the cooperative. The cooperative } \\
\text { clarified income and expenditures and informed its members. As a result, the operation of the cooperatives was efficient and was } \\
\text { able to achieve its objectives. } \\
\text { But when considered separately on each side, it was found that the internal control activities did not affect performances and } \\
\text { operational effectiveness. It may come from the agencies delegate the subordinate personnel to have the authority to approve on } \\
\text { behalf of the senior management in writing. The delegation of power of attorney is a control activity established by management as } \\
\text { a guideline for reviewing the performance. As a result, the control activities do not affect the effectiveness of the operations. }\end{array}$ \\
\hline $\begin{array}{l}\text { 4. Information and } \\
\text { Communications aspect }\end{array}$ & $\begin{array}{l}\text { The agencies prepared complete, accurate and updated information. Also, the executives were able to use the information in their } \\
\text { operations and making decision. As per Chutima Lertlobsiri [10], who found that the university developed and improved the } \\
\text { accounting recording system by implementing a successful program with fast and current processing of financial and accounting } \\
\text { information. This allowed executives to be able to use information for planning and making decision. } \\
\text { When considering each aspect, it was found that information and communications aspect of the internal control system did not } \\
\text { affect the compliance with applicable laws and regulations, since they were not assigned. Chutima Lertlobsiri [10], who found that } \\
\text { the factors of internal control of information and communications aspect were not related with the assigned performance by the } \\
\text { executives to use as a guideline for the operation even if it was fixed or changed the rules and regulations. }\end{array}$ \\
\hline 5. Monitoring aspect & $\begin{array}{l}\text { If the agencies followed up the performance continuously and improved the defects arising from the operations by allowing } \\
\text { personnel to participate in the correction and improvement as well as reported to the executives. It makes operating results in the } \\
\text { agencies were more efficient and effective. Also, it could increase the reliability of the financial reports and be able to comply with } \\
\text { laws and regulations appropriately. As per Nureeya Sanbako [8], who found that the monitoring and assessment of the } \\
\text { performance of the internal control system helped schools to ensure that the existing internal control system was effective and } \\
\text { efficient. Moreover, the executives could use the obtained information with the cooperative appropriately in current situation. }\end{array}$ \\
\hline
\end{tabular}

\section{CONCLUSION}

The study found that all factors affected performances of local governments in Sisaket Province as follows: monitoring, control activities, information and communications, control environment and risk assessment, respectively, with the statistical significance at the level of $\mathrm{p}<0.01$.

\section{REFERENCES}

[1] S. Masarat, Guidelines for Internal Accounting and Financial Control of the Subdistrict Organization Administrations in Mueang District, Buriram Province. Chiang Mai: Chiang Mai University, 2009, pp. 1-2.

[2] S. Kanpudchee, An Analysis of the Internal Control System Efficiency of the Education Institutions under the Office of the Vocational Education Commission in Bangkok. Mahasarakham: Mahasarakham University, 2012.

[3] State Audit Office of the Kingdom of Thailand, Guidelines: Management of the Internal Control System and the Evaluation of Internal Control. Bangkok: System Four Graphics, 2009.

[4] B. Phumkhokrak, Effects of Internal Control Activities on Operational Quality of SMEs in the Northeastern Region. Mahasarakham: Mahasarakham University.2011;1-2.
[5] Department of Local Administration.Handbook of Good Governance Regulations of Local Government Organizations. Bangkok: Agricultural Cooperative Community of Thailand, 2013, pp. 8.

[6] C. Aroonsit, Performances under the Internal Control Standard of Local Government Organizations in Lampang Province. Chiang Mai: Chiang Mai University, 2008, pp. 5-6.

[7] B. Srisa-ard, Foundation for Research, 7th ed. Bangkok: Suwiriiyasat, 2002, pp. 99.

[8] N. Sanbako, Factors of Internal Control Standard Affecting Objective Achievement of Schools under the Jurisdiction of Pattani Primary Educational Service Area Office. Hat Yai: Master of Education in Educational Administration, Prince of Songkla University, 2011.

[9] P. Kayachai, An Internal Control of Saving Groups for the Production of Moo 2 and Moo 17 in Pongheung Village, Huaysak Subdistrict, Muang District, Chaing Rai Province. Chiang Rai: Master of Business Administration, Chiang Rai Rajabhat University, 2008.

[10] C. Lertlobsiri, Factors Affecting Internal Control System for Finance and Accounting of Rajamongkhong Rattanakosin University of Technology. Nakhon Pathom: Master of Accounting, Rajamongkhong University of Technology Rattanakosin, 2008. 